\title{
Fetomaternal outcome in morbidly adherent placenta in a tertiary referral hospital
}

\author{
Amudha Paneerselvam*, Asha Sundaram
}

Department of Obstetrics and Gynecology, Thanjavur Medical College, Thanjavur, Tamil Nadu, India

Received: 11 August 2018

Accepted: 27 September 2018

\section{*Correspondence:}

Dr. Amudha Paneerselvam,

E-mail: amudha70dr@gmail.com

Copyright: (C) the author(s), publisher and licensee Medip Academy. This is an open-access article distributed under the terms of the Creative Commons Attribution Non-Commercial License, which permits unrestricted non-commercial use, distribution, and reproduction in any medium, provided the original work is properly cited.

\begin{abstract}
Background: Morbidly adherent placenta is often associated with major pregnancy complications requiring massive blood transfusions, peripartum hysterectomy, etc. The prior number of caesarean sections and placenta previa are the critical risk factors. The aim of this study is to evaluate the fetomaternal outcome in women with morbidly adherent placenta and to quantify the risk factors predisposing to it.

Methods: This is a retrospective cohort study. The study population comprises women, who had C-section for placenta accreta, increta and percreta at Government Raja Mirasudhar Hospital, Thanjavur from May 2016 to September 2017.

Results: Eighteen women out of 21,083 who delivered during the study period had morbidly adherent placenta with an incidence of $0.085 \%$. The mean gestational age at the time of C-section was 32.4 weeks. Twelve $(66.66 \%)$ out of eighteen women had prior one C-section, two (11.11\%) women had prior 2 C-section and two (11.11\%) women had prior $3 \mathrm{C}$-section.10 cases were diagnosed antenatally by radiological imaging. Seventeen out of eighteen women underwent caesarean hysterectomy $(94.44 \%)$. Average blood loss was 1.8 litres. The mean intraoperative blood transfusions were 3 units of PRBC, 3 units of FFP and 1.4 units of platelet. There was no maternal mortality. The average total hospital stay was 20.46 days. 11 neonates were preterm $(61 \%)$ and 5 neonates were term $(27.74 \%)$. FGR was seen in 2 preterm neonates $(12.5 \%)$. The NICU admission rate was $81 \%(n=13)$. The perinatal mortality rate was $31.25 \%(\mathrm{n}=5)$.

Conclusions: As most of the women ended up in caesarean hysterectomy, early diagnosis will enable appropriate planning for blood components, anaesthetic and surgical resources, thereby reducing adverse fetomaternal outcomes. This will also allow adequate preoperative counselling of the women involved.
\end{abstract}

Keywords: Caesarean hysterectomy, Fetomaternal outcomes, Morbidly adherent placenta

\section{INTRODUCTION}

Morbidly adherent placenta is attributed to the defective decidualisation of the implantation site and the absence of both the decidua basalis and Nita Buch's layer, resulting in direct attachment of the chorionic villi to the myometrium. The incidence of morbidly adherent placenta has increased with the sharp increase in the rate of C-section over the past 2 decades. ${ }^{1,2}$ Placenta previa and the number of prior C-sections is considered the two major risk factors. ${ }^{2}$ Placenta accrete syndromes describe the abnormally implanted, invasive, or adhered placenta. Derivation of accrete comes from the Latin ac + crescere $=$ to grow from adhesion or coalescence, to adhere, or to become attached to. ${ }^{3}$ Variants of placenta accrete syndrome are classified by the depth of trophoblastic growth. Placenta accreta indicates that villi are attached to the myometrium. 
Placenta increta indicates invasion of myometrium by villi and Placenta percreta defines villi that penetrate through the myometrium and to or through the serosa. ${ }^{4}$ In clinical practice, these three variants are encountered in an approximate ratio of 80:15:5, respectively. ${ }^{5}$ In all three varieties, abnormal adherence may involve all lobulestotal placenta accreta. If all or part of a single lobule is abnormally attached, it is described as a focal placenta accreta.

Morbidly adherent placenta is associated with major pregnancy complications like life threatening maternal haemorrhage, large volume blood transfusion, peripartum hysterectomy and surgical injury to adjacent organs and neurovascular structures, ARDS, acute transfusion reactions, electrolyte imbalance and renal failure. ${ }^{6}$ The aim of this study is to evaluate the fetomaternal outcome among women with morbidly adherent placenta and to quantify the risk factors predisposing to it.

\section{METHODS}

This study was conducted at Department of Obstetrics and Gynaecology, Government Raja Mirasudhar Hospital, Thanjavur Medical College, Thanjavur.

Study population: women, who had C-section for placenta accreta, increta and percreta at Government Raja Mirasudhar Hospital, Thanjavur. Study period: May 2016 to September 2017. Study design: retrospective study.

\section{Methodology}

The following details were collected regarding the pregnant women included in the study:

- Obstetric history:

1. Parity.

2. Gestational age.

3. Past history: previous C-section, prev D and C, prev. myomectomy, prev. H/O Placenta previa.

4. Antenatal History: H/o APH, H/o blood transfusion.

- Investigations: Hemoglobin, blood grouping and typing, coagulation profile.

\section{Obstetric USG:}

1. To determine the position of placenta and the type of placenta previa.

2. To look for features suggestive of MAP: loss of the normal hypoechoic retroplacental zone between the placenta and uterus, placental vascular lacunae.

3. Doppler colour flow to predict myometrial invasion.

4. Placental bulging into the posterior bladder wall.

5. MRI-abdomen and pelvis, when the USG findings are inconclusive.
- Operative events: The following events were recorded:

1. C-section- emergency/elective.

2. Estimated blood loss.

3. Blood and blood products transfused.

4. Procedures needed to control bleeding.

5. Operative time.

6. Injury to bowel, bladder, ureter and neurovascular injury.

7. Caesarean hysterectomy.

- Post-operative maternal morbidities.

- Total blood and blood products transfused.

- Total hospital stay.

- Neonatal outcome: The following details were recorded with regard to the neonates:

Term/preterm, birth weight, perinatal mortality and its cause, antenatal steroid administration.

\section{RESULTS}

\section{Maternal outcome}

The total number of deliveries during the study period was 21,083 of which 18 women were diagnosed with morbidly adherent placenta with an incidence of $0.085 \%$. Fourteen women were diagnosed with placenta accreta, 3 with placenta percreta and 1 with placenta increta. The mean age of the cohort was 30.15 years with mean parity of 2.61, among whom 3 women were grand multipara. The mean gestational age at the time of C-section was 32.4 weeks. Sixteen women $(88.88 \%)$ had previous Csection and $1(5.55 \%)$ had a scarred uterus following previous uterine rupture. Twelve $(66.66 \%)$ women had one prior C-section, two $(11.11 \%)$ women had 2 prior $\mathrm{C}$ section and two (11.11\%) women had three prior $\mathrm{C}$ section. The mean number of C-section was 1.22.

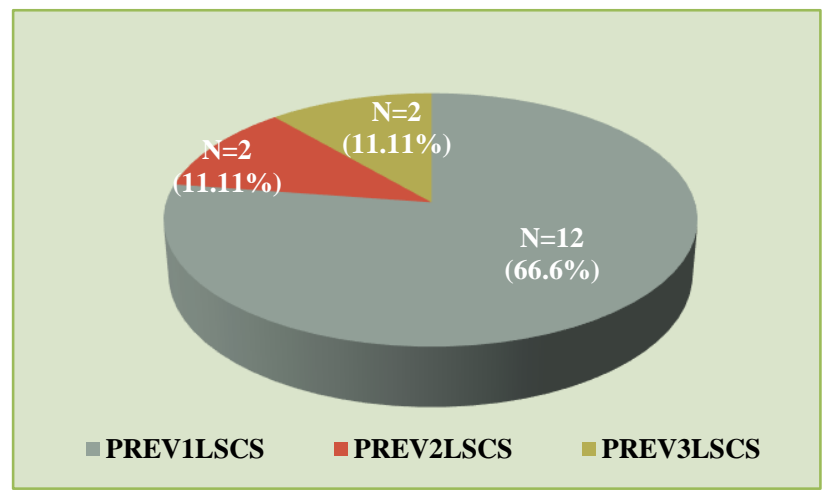

Figure 1: Incidence of MAP among women with previous C-section. 
Fifteen women presented with antepartum haemorrhage and the mean antenatal blood transfusion was 1.3 units of PRBC. Eight out of 14 women with placenta accreta, 1 with placenta increta were diagnosed antenatally by USG and 1 case of placenta increta and 1 out of 3 cases of placenta percreta were confirmed antenatally by MRI.

Seventeen out of 18 women underwent hysterectomy, while in 1 woman with focal placenta accreta, uterine conservation was possible. All the 18 women had operative procedures performed on an emergency basis. Massive blood loss was a prominent feature in present study with an average blood loss of 1.8 litres, and an average operative time of 2 hours. The mean perioperative blood transfusion was 3 units of packed cells, 3 units of FFP and 1.4 units of platelets.

Intraoperative bladder injury occurred in 5 cases $(27.77 \%)$ requiring an average CBD of 14 days. Partial bladder excision with vesicostomy closure was done in one case of percreta. The mean postop PRBC transfusion was 1.3 units, mean FFP transfused was 1.3 and the mean platelets transfused was 1 unit. All 18 women were managed in intensive care unit postoperatively. They had a mean pre-operative hospital stay of 6.15 days and postoperative stay of 14.31 days. There was no maternal mortality.

\section{Neonatal outcome}

Eleven out of 18 neonates were premature $(61 \%)$ while 5 $(27.74 \%)$ were term neonates. Neonates had an average birth weight of $1.7 \mathrm{~kg}$. Among the 16 women, 10 women received complete dose of antenatal steroids. The NICU admission rate was $81 \%(n=13)$. There were 2 preterm intrauterine fetal demise. Fetal growth restriction was seen in $12.5 \%(n=2)$ of preterm neonates. The perinatal mortality rate was $31.25 \% \quad(n=5)$. Respiratory distress syndrome was the leading cause of neonatal death accounting for $80 \%(n=4)$ and sepsis in $20 \%(n=1)$.

\section{DISCUSSION}

The incidence of placenta accreta in the literature varies between $0.001 \%$ to $0.9 \%$ of deliveries. It is now an increasingly common and potentially dangerous obstetric event. In the current study the overall incidence of morbidly adherent placenta was $0.085 \%$ i.e., 1 in 1171 deliveries.

The incidence of morbidly adherent placenta reported by $\mathrm{Wu}$ et al was 1:533 births for the period from 1982 to 2002 which was associated with a sharp increase in csection rates from $12.5 \%$ (1982) to $23.5 \% .^{7}$ Gielchinsky et al reported an incidence of $1: 111 .^{8}$ Hung et al reported an incidence of $1: 334 .^{9}$ In this study, previous C-section appeared to be the most important risk factor accounting for $88.8 \%$ of cases followed by placenta previa which accounted for $83.3 \%$ of the cases.
Table 1: Demographic characteristics of patients $(\mathrm{N}=18)$.

\begin{tabular}{|ll|}
\hline Characteristics & Number \\
\hline Mean age (years) & 30.15 \\
\hline Grand multiparity & $3(16.66 \%)$ \\
\hline Previous 1 LSCS & $12(66.66 \%)$ \\
\hline Previous 2 LSCS & $2(11.11 \%)$ \\
\hline Previous 3 LSCS & $2(11.11 \%)$ \\
\hline Placenta previa & $15(83.33 \%)$ \\
\hline History of D and C & $2(11.11 \%)$ \\
\hline
\end{tabular}

Miller et al reported an incidence of $9.3 \%$ of placenta accrete among women with placenta previa. ${ }^{10}$ In present study, the incidence of placenta accreta was drastically higher among women with placenta previa (88.88\%). History of $\mathrm{D}$ and $\mathrm{C}$ was noted in 2 women and previous history of rupture uterus with rent closure was present in 1 woman. Bencaiova $G$ et al reported significant association of previous uterine intervention in the form of $\mathrm{D}$ and $\mathrm{C}$, uterine surgery other than $\mathrm{C}$-section with adherent placenta. ${ }^{11}$

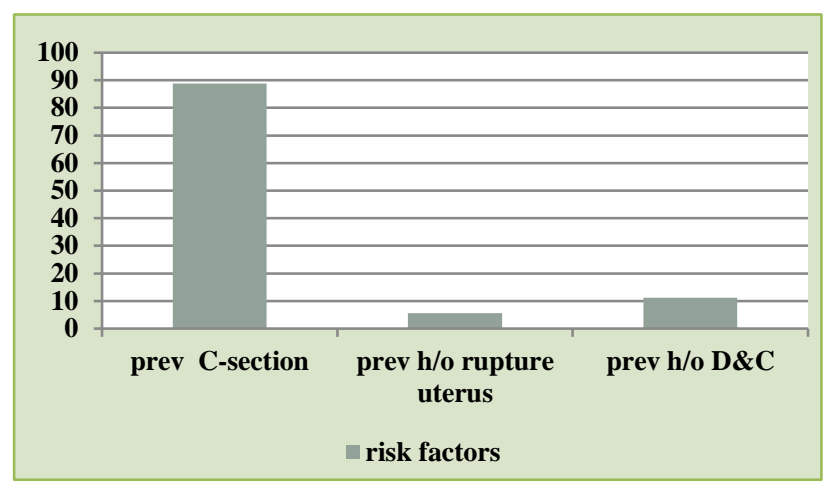

Figure 2: Risk factors for morbidly adherent placenta.

Clark et al stated that the risk of placenta accreta was $24 \%$ with a placenta previa and one caesarean delivery and that this risk increased to $67 \%$ with a placenta previa and four caesarean delivery. ${ }^{12} \mathrm{~A}$ similar observation was made in present study wherein 16 out of 18 women had previous c-section, among whom 12 had previous $1 \mathrm{c}$ section $(66.6 \%), 2$ had previous $2 \mathrm{c}$-section and another 2 had previous $3 \mathrm{c}$-section.

Chattopadhyay SK et al reported that the risk of morbidly adherent placenta increases with the number of previous c-section. ${ }^{13}$ The exact pathogenesis of morbidly adherent placenta is unknown. Garmi et al showed in vitro that an induced sharp decidual incision irritating the invivo process, that is c-section, significantly increased the invasive potential of trophoblast cells. ${ }^{14}$ Antenatal diagnosis was possible in 8 cases of placenta accreta and 1 case of placenta increta by USG and 1 case of placenta increta and 1 case of placenta percreta were confirmed antenatally by MRI. 
The USG features observed in present study were thinning of the myometrium overlying the placenta and irregularly shaped placental lacunae. Aitken et al reported that MRI had a higher prediction rate of abnormal invasive placentation compared to ultrasound $(91.9 \%$ versus $98.4 \%) .{ }^{15}$ Ibrahim et al found that USG and MRI had no significant difference in accuracy in diagnosing abnormal placentation (97-100\% versus 94-100\%). ${ }^{16}$ They concluded that MRI had higher accuracy compared to USG in diagnosing myometrial invasion and the type of abnormal placentation $(73.5 \%$ versus $47 \%) .{ }^{15,16}$ Out of the 18 cases, 11 cases were diagnosed antenatally $(61 \%)$.

Fifteen women $(83.3 \%)$ presented with antepartum haemorrhage and all of the operative procedures were performed on an emergency basis. Massive blood loss was a prominent feature with an average blood loss of 1.8 litres. Prophylactic antibiotics were given with repeat doses after 2 hours of surgery or $1500 \mathrm{ml}$ of estimated blood loss to all cases as recommended by ACOG. ${ }^{6}$ The mean operative time was 2 hours. 17 out of 18 women underwent hysterectomy while in one woman with focal placenta accreta uterus was conserved. Jauniaux E et al reported c-hysterectomy rate of $89.7 \%{ }^{17}$. The caesarean hysterectomy rate in present study was $94.4 \%$. Eller et al reported that when accreta was suspected a scheduled Chysterectomy without attempting placenta removal was associated with a significantly decreased rate of early morbidity compared with cases in which placenta removal was attempted. ${ }^{18}$ The average intra operative blood transfusion was 3 units of PRBC, 3 units of FFP and 1.4 units of platelets.

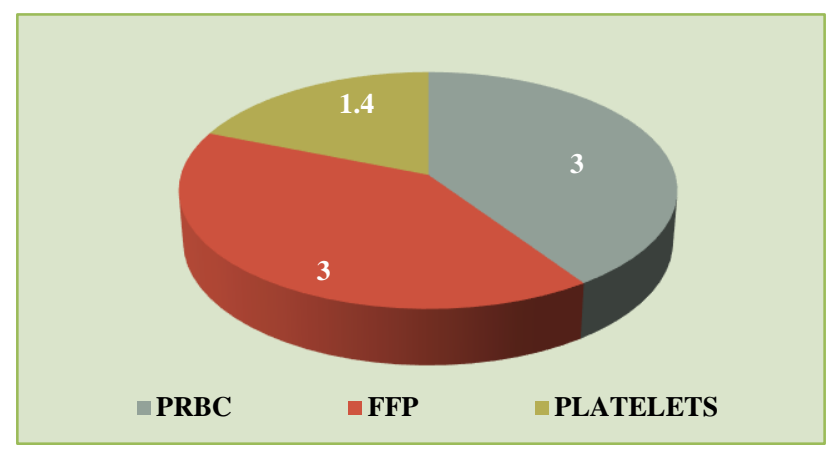

Figure 3: Mean intraoperative blood transfusion.

Intra operative bladder injury was seen in 5 cases (27.7\%) requiring an average CBD of 14 days. Suprapubic cystostomy was done in 2 cases. Bilateral DJ stenting was done intra operatively in 1 woman. Partial bladder excision with vesicotomy closure was done in one woman. Strategies like uterotonics administration, bilateral uterine artery ligation, internal iliac artery ligation, were attempted to reduce intra operative blood loss. The total average PRBC transfused was 5.6 units, average FFP transfused was 4.3 units and average platelets transfused was 2.4 units.

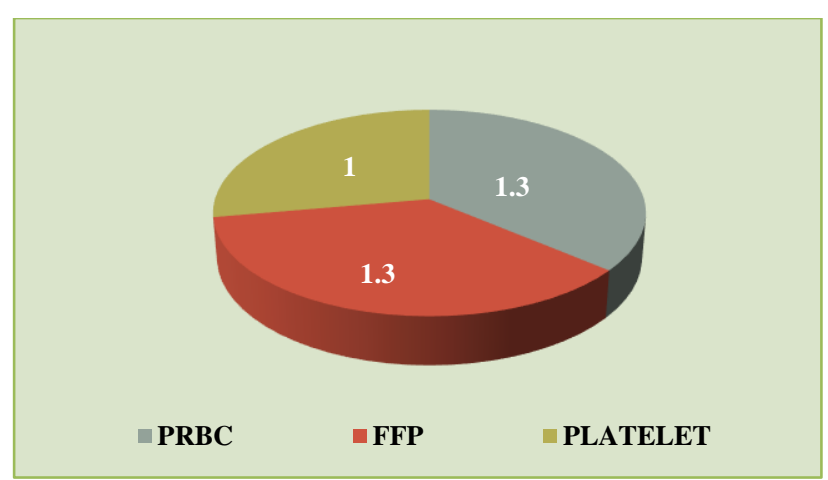

Figure 4: Mean post-operative blood transfusion.

A multidisciplinary team approach consisting of two obstetric surgeons, anesthetist, neonatologist and urologist were routinely involved in almost all the cases in this study. Balayla et al suggested that surgical management via caesarean hysterectomy should be considered as the gold standard as it is recommended by the ACOG19. In present study this was followed. There was no maternal mortality in present study. They had a mean postoperative stay of 14.31 days with an average total hospital stay of 20.46 days. The common complication patients encountered during their postoperative stay was electrolyte imbalance.

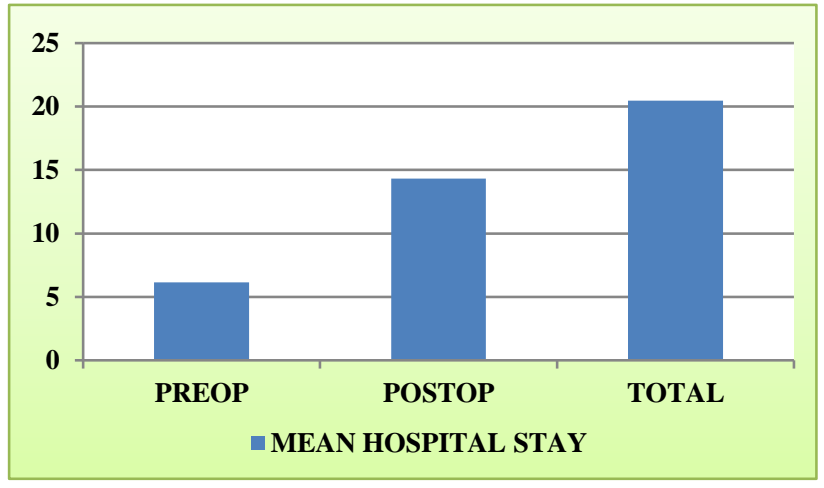

Figure 5: Mean hospital stay.

Ten out of 16 women received complete dose of antenatal corticosteroids. More than $75 \%$ of present women were delivered before 37 weeks and the NICU admission rate was $81 \%(n=13)$. The neonates had an average birth weight of $1.7 \mathrm{~kg}$. In the study done by Balayla et al the NICU admission rate was $86 \% .{ }^{19}$ In present study the NICU admission rate was lower comparatively. Neonatal asphyxia and hypoxia secondary to severe haemorrhage was more marked before 34 weeks. The perinatal mortality rate was $31.25 \% \quad(n=5)$ and there were two preterm Intrauterine death on admission. Harper LM et al reported FGR rate of $20.2 \%$ in women with complete placenta previa. $^{20}$ In present study the FGR rate was $12.5 \%(n=2)$ in women with complete placenta previa. 


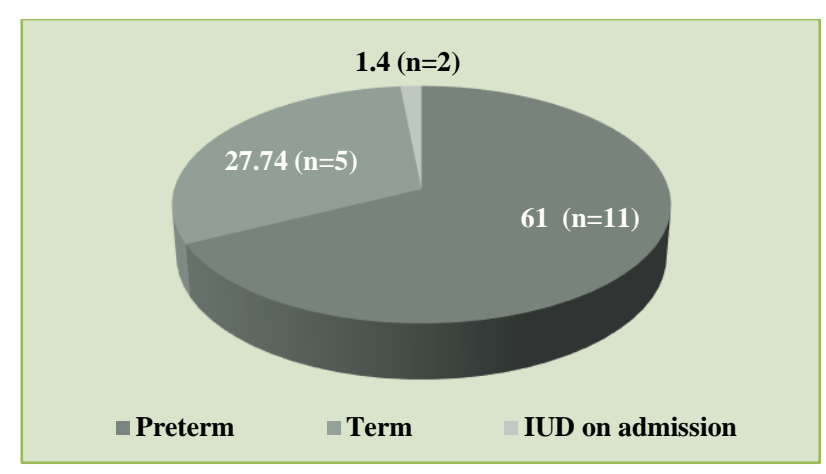

Figure 6: Neonatal outcome.

However, the study has some limitations, i.e., it was retrospective in nature and included a relatively small number of patients. The non-availability of MRI services $24 * 7$ has significantly decreased the number of patients diagnosed preoperatively and had led to significant morbidities.

\section{CONCLUSION}

Prenatal diagnosis and adequate pre-delivery planning particularly in high risk populations, may be indicated for the reduction of adverse maternal and neonatal outcomes. Since most of the women ended up in caesarean hysterectomy, early diagnosis with appropriate investigations like MRI would lead to decrease in morbidity and more efficient management of the patient as it will allow for appropriate planning for blood components, anaesthetic and surgical resources and adequate counselling of the women involved.

Funding: No funding sources

Conflict of interest: None declared

Ethical approval: Not required

\section{REFERENCES}

1. Cheng KK, Lee MM. Rising incidence of morbidly adherent placenta and its association with previous caesarean section: a 15-year analysis in a tertiary hospital in Hong Kong. Hong Kong Med J. 2015;21(6):511-7.

2. Aggarwal R, Suneja A, Vaid NB, Yadav P, Sharma A, Mishra K. Morbidly adherent placenta: a critical review. J Obstet Gynecol India. 2012;62(1):57-61.

3. Benirschke K, Burton J, Baergen RN. Non-villous parts and trophoblast invasion. In: Pathology of the Human Placenta, $6^{\text {th }}$ ed. New York, Springer; 2012: 154-240.

4. Cunningham, Leveno, Bloom, Spong, Dashe, Hoffman, Casey, Spong. Obstetrical Haemorrhage. In: Williams Obstetrics, $25^{\text {th }}$ ed. New York, NY: McGraw-Hill; 2018:777-779.

5. Wong HS, Cheung YK, Zuccollo J, Tait J, Pringle $\mathrm{KC}$. Evaluation of sonographic diagnostic criteria for placenta accreta. J Clinic Ultrasound. 2008;36(9):551-9.

6. Committee Opinion No. 529. American College of Obstetricians and Gynecologists. Placenta accreta. Obstet Gynecol. 2012;120:207-11.

7. Wu S, Kocherginsky M, Hibbard JU. Abnormal placentation: Twenty-year analysis. Am J Obstet Gynecol. 2005;192:1458-61.

8. Gielchinsky Y, Rojansky N, Fasouliotis SJ, Ezra Y. Placenta accreta: Summary of 10 years: A survey of 310 cases. Placenta 2002;23:210-4.

9. Hung TH, Shau WY, Hsieh CC, Chiu TH, Hsujj, Hsieh TT. Risk factors for placenta accrete. Obstet Gynecol. 1999;93:545-50.

10. Miller DA, Chollet JA, Goodwin TM. Clinical risk factors for placenta previa-placenta accreta. Am J Obstet Gynecol. 1997;177:210-6.

11. Bencaiova G, Burkhardt T, Beinder E. Abnormal placental invasion experience at 1 center. J Reprod Med. 2007;52(8):709-14.

12. Clark SL, Koonings PP, Phelan JP. Placenta previa/accrete and prior cesarean section. Obstet Gynecol. 1985;66:89.

13. Chattopadhyay SK, Kharif H, Sherbeeni MM. Placenta praevia and accreta after previous caesarean section. Eur J Obstet Gynecol Reprod Biol. 1993;52(3):151-6.

14. Garmi G, Goldman S, Shalev E, Salim R. The effects of decidual injury on the invasion potential of trophoblastic cells. Obstet Gynecol. 2011;117:55.

15. Aitken K, Allen L, Pantazi S, Kingdom J, Keating S, Pollard L, et al. MRI significantly improves disease staging to direct surgical planning for abnormal invasive placentation: a single centre experience. J Obstet Gynaecol Canada. 2016;38(3):246-51.

16. Alagebally AM, Yosef RR, Padr SS, AlObeidly A, Szmigielski W, Al Ibrahim AA. The value of ultrasound and magnetic resonance imaging in diagnostics and prediction of morbidity in cases of placenta previa with abnormal placentation. Pol J Radiol. 2014;79:409-6.

17. Jauniaux E, Jurkovic D. Placenta accreta: pathogenesis of a $20^{\text {th }}$ century iatrogenic uterine disease. Placenta. 2012;33:244-51.

18. Eller AG, Porter TF, Soisson P, Silver RM. Optimal management strategies for placenta accreta. $\mathrm{Br} \mathrm{J}$ Obstet Gynecol. 2009;116:648-54.

19. Balayla J, Bondarenko HD. Placenta accrete and the risk of adverse maternal and neonatal outcomes. J Perinat Med. 2013;41:141-9.

20. Harper LM, Odibo AO, Macones GA, Crane JP, Cahill AG. Effect of placenta pevia on fetal growth. Am J Obstet Gynecol. 2010;203:330-e1.

Cite this article as: Paneerselvam A, Sundaram A. Fetomaternal outcome in morbidly adherent placenta in a tertiary referral hospital. Int J Reprod Contracept Obstet Gynecol 2018;7:4540-4. 